\title{
Monitoring of Haemostasis during Liver Transplantation
}

\author{
Matteo Garcovich ${ }^{* 1}$, Andrew Kenneth Burroughs ${ }^{2}$, Chiara Campanale ${ }^{1}$ and Antonio Gasbarrini ${ }^{1}$ \\ ${ }^{1}$ Internal Medicine Department, Gemelli Hospital, Catholic University of Sacred Heart, Rome, Italy \\ ${ }^{2}$ Sheila Sherlock Liver Centre, Royal Free and University College School of Medicine, London, UK
}

\begin{abstract}
When end stage liver disease occurs, liver transplantation is the only effective treatment available. In the past, liver transplantation was frequently accompanied by considerable bleeding complications and massive transfusion requirements, while only in recent years advances in operative management and a better understanding of the pathophysiology of coagulation have determined a better outcome for this major surgery. In addition, accumulating evidence shows that the overall haemostatic function in patients with cirrhosis facing liver transplantation may not be shifted towards a bleeding diathesis as traditionally believed, but that both bleeding episodes and thrombotic events may take place as major peri- and post-operative complications in patients undergoing liver surgery. The aim of this review paper is to offer an overview of recent developments that have gradually improved our understanding about the changes that may occur in the haemostatic system of patients undergoing liver transplantation, taking into account the best way to monitor them.
\end{abstract}

Keywords: Liver transplantation, haemostasis, hypocoagulability, hypercoagulability, point-of-care assay.

\section{INTRODUCTION}

Liver transplantation (LT) is the main treatment for patients with end-stage acute and chronic liver disease not responsive to medical treatment and associated with poor prognosis. In the past, LT was frequently accompanied by considerable bleeding complications and massive transfusion requirements and was regarded as a long and risky surgical procedure [1,2]. Advances in surgical techniques, graft preservation and operative managements have improved the success rate of this major surgery. Particularly, a better and thorough understanding of the pathophysiology of coagulation has contributed to the development of specific techniques for monitoring the coagulation system with consequent selection of rational therapies to improve haemostatic function in these patients. Recent studies and developments have gradually changed our understanding about the haemostatic system and the changes that may occur in patients with liver disease. In addition, LT itself is frequently complicated by haemostatic defects associated with perioperative coagulopathies, surgical bleeding, and the poor or recovering function of the new graft. Therefore, coagulation and haemostasis in the patient with liver disease facing an LT is influenced by multiple events, which may lead to bleeding complications, but may also result in a hypercoagulable state.

\section{THE HAEMOSTATIC BALANCE - BLEEDING AND THROMBOEMBOLIC COMPLICATIONS}

The liver plays a key role in blood coagulation being involved in both the primary and secondary haemostasis [3]. Normally, haemostasis is tightly regulated and in balance

\footnotetext{
*Address correspondence to this author at the Internal Medicine Department, Catholic University of Rome, Largo A. Gemelli 8, 00168 Rome, Italy; Tel: ++39 063015 6018; E-mail: matteogarcovich@yahoo.it
}

between a prothrombotic and an antithrombotic drive. In patients with severe liver disease and during LT, multiple changes in several hemostatic processes occur [4]. These changes are related to both prohaemostatic and antihaemostatic pathways disturbing the haemostatic "status quo", tilting the balance to either a bleeding diathesis or thrombotic disorders [5]. It is clear that the coagulopathy of liver disease is extremely complex and unpredictable. The conventional tests of the clotting cascade such as prothrombin time (PT), activated partial thromboplastin time (APTT) and international normalized ratio (INR) do not reflect this haemostatic balance, nor risk of bleeding nor thrombosis [6]. Until recently, the derangement of peripheral indices of coagulation in patients with chronic liver disease has been thought to be causally related to the bleeding events seen in these patients. However in reality, there is relatively poor correlation between invasive procedures, peripheral indices of coagulation and risk of bleeding [7,8]. Moreover, it has been shown that PT and APTT are inadequate to reflect the balance of coagulation as it occurs in vivo, as the naturally occurring anticoagulants like protein $\mathrm{C}$ and $\mathrm{S}$, antithrombin and tissue factor pathway inhibitor (TFPI) are reduced in parallel with procoagulant factors [9]. Recent findings have challenged the well-accepted concept that liver disease is accompanied by a bleeding tendency $[4,10,11]$. Accumulating evidence shows that the overall haemostatic function in patients with cirrhosis may not be as abnormal as traditionally believed and it is clear that patients with cirrhosis are not exempt from developing thrombotic complications. For instance, portal vein thrombosis is not an infrequent event [12], while peripheral deep vein thrombosis (DVT) and pulmonary embolism (PE) occur in patients with cirrhosis by an incidence of $0.5 \%$ to $1.0 \%$ for DVT or PE [13]. Thus both bleeding episodes and thrombotic events represent a major peri- and post-operative challenge in patients undergoing LT $[14,15]$. 


\section{Hypocoagulablity}

In major surgical procedures involving the liver, such as partial liver resection and LT, bleeding is frequent. The transfusion of blood products and perioperative blood loss has been identified as an important cause of morbidity and mortality after LT [16-18]. During the past two decades, improvements in operative management, surgical techniques and graft preservation have contributed to a significant decrease in blood loss and transfusion requirements in liver transplant recipients to such an extent that in current practice a significant proportion of patients receive no blood during surgery $[19,20]$. To understand risk factors associated with bleeding that could be causally associated one requires studies which define predictors related to bleeding. However most studies have not studied these sufficiently well $[14,21,22]$.

\section{Hypercoagulability}

In contrast to the well known bleeding diathesis, thromboembolic complications are less frequently encountered intraoperatively during LT. Nonetheless, thromboembolic complications in patients undergoing OLT have been reported since the very early experiences [23]. These complications can be divided into liver-related vascular thrombosis, such as portal vein thrombosis and hepatic artery thrombosis, and systemic thromboembolic processes, such as PE and intracardiac thrombosis (ICT) $[15,24]$. Formation of thrombi in the central venous and pulmonary circulation seems to occur more frequently during LT than during any other type of major surgery. Although the estimated incidence of PE or ICT in liver transplant recipients is low (around 1-1.5\%) $[25,26]$, these complications are potentially fatal, and therefore of great clinical relevance. Although a rebalanced haemostatic system towards thrombosis may explain the procoagulant tendency of patients with liver disease, surgical factors are often considered a main determinant of LTrelated vascular thrombosis. Also, it has been suggested that thrombotic complications in the early postoperative period can be related to various transplantation-related triggers that activate coagulation or induce platelet activation [27]. Transplantation-related triggers include surgical damage, release of activators form the donor liver, stasis of blood during clamping of vessels and systemic inflammatory responses [15]. This ongoing initiation of coagulation may not be balanced properly by the anticoagulant and profibrinolytic systems. Indeed, an inbalance between prohemostatic and antihemostatic systems is seen in the first days after OLT, resulting in a hypercoagulable state [28]. A hypercoagulable state, as monitored by postoperative thromboelastography (TEG), also correlated also with the risk of developing thrombotic complications in patients undergoing hepatic resection for living related liver transplantation [29]. Systemic thromboembolic complications like PE and ICT may have additional underlying mechanisms: the use of venovenous bypass, the migration of thrombi formed around pulmonary artery or central venous catheters, or at the site of a transjugular intrahepatic portosystemic shunt (TIPS), and the use of hemostatic agents (i.e. fresh-frozen plasma, platelets, recombinant factor VIIa and antifibrinolytic drugs) [15].

\section{MONITORING HAEMOSTASIS DURING LT}

Haemostatic abnormalities occurring during liver transplantation are usually divided according with the surgical phases. These are traditionally classified into: dissection/preanhepatic phase, anhepatic phase, post-reperfusion phase and the early post-operative period.

\section{Dissection/Pre-Anhepatic Stage}

The initial extensive surgical trauma is characterized by dissection of adhesions in the abdominal cavity and by the transection of many collateral vessels. This first stage is usually characterized by minor blood loss, with the exception of patients who have intra-abdominal adhesions caused by previous upper abdominal surgery and patients who have significant portal hypertension, who generally have a higher bleeding tendency. Vascular injury and impaired clearance of activated coagulation factors caused by decreased hepatic blood flow may result in excessive activation of coagulation and consumptive coagulopathy, while surgical bleeding may deplete coagulation proteins and platelets inducing dilutional coagulopahty [30]. Therefore, the mild coagulation abnormalities and the blood losses occurring during the dissection phase are mainly correlated with the surgical technique, although the baseline hypocoagulable state and the aetiology of liver disease can also influence the blood product requirement [31]. Other factors like hypothermia, ionized hypocalcemia and $\mathrm{pH}$ changes may also impair coagulation [32].

\section{Anhepatic Phase}

Although during this phase no important surgical blood loss should be seen because of appropriate clamping of vessels, significant haemostatic changes may occur nonetheless. Platelets and coagulation factors are depleted by surgical bleeding together with the absence of the hepatic synthetic and clearance function. In addition to this, the release of tissue thromboplastin and the absence of the hepatic clearance of activated coagulation factors may cause excessive activation of coagulation. This is observed by gradual increases in thrombin-antithrombin-III complex and fibrin degradation products [33]. However, clinically significant intravascular coagulation or thrombosis is uncommon during this period. Also, hyperfibrinolysis has been demonstrated in many studies, due to net increase in tissue plasminogen activator (tPA) derived from endothelial cells. Again, this tPA is not cleared due to a the absence of the liver at this time [34]. The presence of an active fibrinolytic process has been demonstrated by simultaneous decrease of $\alpha 2$-antiplasmin and plasminogen activity, and a concomitant increase in fibrin and fibrinogen degradation products [35]. In any case, regardless of impairment of synthetic and clearance function, early studies failed to show dramatic changes in PT and PTT [36,37].

\section{Reperfusion Phase}

Reperfusion of the liver is a crucial point in this major surgery and usually leads to profound coagulation abnormalities. Indeed, diffuse and uncontrollable bleeding may occur in some patients within minutes after reperfusion [38]. 
The cause of marked deterioration in coagulation that accompanies reperfusion is multifactorial and has been identified as DIC, hyperfibrinolysis, platelet activation, trapping of platelets in the graft, and the presence of heparin-like effect (HLE) [37]. From the donor point of view, a poor quality of the transplanted organ has been associated with signs of DIC after graft reperfusion [39]. In addition, an increase in fibrinolysis has been felt to be an important phenomenon responsible for bleeding during OLT, usually diminishing within 60 min after graft reperfusion if the grafted liver begins to function, although a sustained increased fibrinolytic response can be seen in marginal donors [40]. The release and washout of plasminogen activators from the graft have been considered responsible for the increased levels of tPA at reperfusion, as the hepatic endothelium is a rich source of these activators [41]. Fibrinolysis occurs in approximately $80 \%$ of patients with clinically significant fibrinolysis and bleeding observed in about $40 \%$ of patients [42].

Release of heparin or heparin-like substances has been noted for many years after reperfusion of the donor liver, although its significance has never been fully elucidated $[43,44]$. An exogenous source of heparinoids released after reperfusion is provided by the residual heparin bound to the endothelium of the donor vessels, as the donor liver is perfused with heparin before clamping. In addition to this, there is probably also an endogenous source of heparinoids, because in some recipients they are present before incision and also because evidence of heparin-like activity has been reported after reperfusion even in the absence of heparin infusion in the donor liver [40]. Moreover, an increased release of heparinoids is thought to occur from activation of macrophages following the ischemia reperfusion injury [45]. Before the advent of heparinase-coated cups in TEG, a useful monitor of coagulation abnormalities during liver transplant, the prevalence of HLE after reperfusion was reported to be between $25 \%$ and $95 \%$ of cases [46-48]. In the last 10 years, large series using heparinase I-modified TEG have reported the prevalence of HLE among patients undergoing liver transplant $[43,49,50]$, with the most recent including 211 patients and showing a prevalence of $30 \%, 6 \%$ being severe (i.e., a correction of the TEG by heparinase by more than $80 \%$ ). This study has also demonstrated that although HLE is detected by TEG in many liver transplant patients both before and after reperfusion of the donor graft, its presence does not correlate with an increase in blood requirement [51]. Usually the release of these heparin-like substances from the grafted liver results in moderate to severe heparin effect and may last for 60 to 120 minutes [52]. A higher prevalence of HLE is seen in patients who have acute liver failure [53] or primary non-function of the liver graft and in patients urgently listed for retransplant [51], but the cause is still unknown. The presence of heparinoids is correlated with the severity of liver disease $[50,54]$, probably because of decreased cleavage by the liver of endogenous and exogenous heparin heparinoids, while the etiology of liver disease does not seem to influence the presence and severity of HLE [43].

Platelets also have a role in haemostatic abnormalities during this surgical stage. After graft reperfusion, the platelet count decreases by $30 \%$ to $55 \%$ because of entrapment of platelets in the liver graft [55-57]. Moreover, the release of tPA from the graft results in proteolysis of key platelet receptors [41] and the activation of platelets after graft reperfusion contributes to deterioration of their function during LT [55,58]. In addition, some of the initially sequestrated and partially activated platelets will be released again from the liver into the circulation at a later stage after reperfusion [59]. As these partially activated platelets will have severely reduced haemostatic capacity, measurement of the platelet count does not reflect the platelet-dependent hemostatic capacity [60].

\section{Postoperative Period}

In the early postoperative period after LT, thrombocytopenia is common, mainly due to platelet activation and consumption following graft reperfusion [61]. Platelet count and coagulation factors usually increase steadily toward normal levels, if normal synthetic function of the liver is restored in the first few days after transplantation. In fact, thrombopoietin (TPO) levels increase significantly on the first day post-OLT, following by immature bone marrow megakaryocytes after 3 days and new circulating platelets after 5 days, with normalization of platelet count achieved after 14 days [62,63]. Levels of bilirubin, cold ischemia time or episodes of rejection do not seem to influence TPO levels [64]. Persistence of thrombocytopenia can be seen in some patients, which can be ascribed to persistent splenomegaly in some [65]. In adult-to-adult living donor liver transplantation, persistently elevated portal venous pressure and hypersplenism due to relatively small graft size have been associated with post-LT thrombocytopenia. Also, post-operative thrombocytopenia in these patients may be explained by relatively low thrombopoietin production [66]. In a small proportion of patients the rise in the platelet count following liver transplantation is excessive, resulting in thrombocytosis, although current evidence suggests that the thrombocytosis is transient and not associated with an increased risk of thrombotic complications like hepatic artery thrombosis [67].

\section{ASSESSMENT AND MONITORING OF COAGULA- TION}

Patients undergoing liver transplantation are usually characterized by an impaired synthesis of most of the coagulation factors with complex haemostatic defects including primary hemostasis, coagulation and fibrinolysis. These defects are usually documented by the measurement the prolongation of such global tests as the PT and the aPTT. A causal relationship between abnormal tests and bleeding complications often associated with liver disesases has become an accepted paradigm, with hepatologists and hepatobiliary surgeons ordering laboratory testing to make decisions about the management of the coagulation disturbances (and using procoagulant drugs as prophylactic or interventional measures). However as stated before, recent data indicate that this presumed association is not backed by evidence. In fact, the poor prediction of bleeding in the setting of major surgery raises questions about the usefulness of conventional testing [68]. Alternative tests mimicking more closely what occurs in vivo are already used and 
investigated to determine their value in the management of haemostasis in liver transplantation, particularly because at present time there are no "gold standard" coagulation tests that strongly correlate with or predict surgical bleeding in OLT $[14,69]$. Consequently, there is marked institutional variability in methods of coagulation management of transplant centers, due to different methods of coagulation monitoring and varying thresholds for transfusion of blood products $[70,71]$.

\section{COVENTIONAL ASSAYS}

Although a variety of conventional laboratory tests are performed to identify the type and severity of the coagulation disorders, most tests have limited application during liver transplantation [30].

\section{Prothrombin Time and INR}

The prothrombin time (PT), was developed by Armand Quick in 1935 for investigating patients with liver disease [72]. PT measures the time to form the initial clot after tissue thromboplastin is added to the recalcified, citrated blood specimen, and is an expression of the extrinsic pathway. The $\mathrm{PT}$ is responsive to congenital or acquired deficiencies of factors VII, X, V, and II and fibrinogen. Clinical use of PT is limited during liver transplantation, because it is prolonged in most patients during surgery. Another way of expressing results of the PT is the international normalized ratio (INR), in which the ratio is raised to a power equal to the international sensitivity index (ISI) of the measuring system used for testing. In the setting of liver transplantation, the PT/INR test is one of the components needed to compose the MELD score, which represents the basis to prioritize patients for liver transplantation in some countries [73]. Obviously, the use of the PT test in this regard has been questioned. Firstly, there is no standardization of results across different laboratories for PT. Secondly [74], while the PT results expressed as international normalized ratio (INR) are valid for patients on vitamin $\mathrm{K}$ antagonists [75], they are less valid for patients with chronic liver disease [76]. Studies using the INR scale to harmonize results for patients who have liver disease have been carried out, to help resolve this issue for this category of patients $[77,78]$. However use of a "liver INR" is not very applicable.

\section{Activated Partial Thromboplastin Time}

The aPTT was first developed in 1953 [79] and then modified in 1961 [80]. This test reflects the time, in seconds, needed for the plasma to clot when mixed with a particulate or soluble activator of the contact coagulation factors and negatively charged phospholipids as platelet substitutes. Except for factors VII and XIII, the aPTT is responsive to congenital or acquired deficiencies of all coagulation factors. The results are expressed as a coagulation time or a ratio (patient-to-normal coagulation time) and they vary according to the commercial measuring system used for testing. In contrast to INR, no standardization scheme has been devised to harmonize results across laboratories. Although it is sensitive in monitoring heparin activity, its clinical application in liver transplantation is limited as its intraoperative changes are similar to those of PT.

\section{Platelets}

During liver transplantation, a certain amount of platelets is required to maintain hemostasis. However, in patients with liver disease platelets number and function are often compromised, and during transplantation further alterations of platelets may occur, contributing to increased blood loss $[81,82]$. A simple, reliable and reproducible platelet function test is the Platelet Function Analyzer [83,84]. It evaluates primary hemostasis by measuring the time required for whole blood to occlude an aperture in the test cartridge membrane that is coated with platelet agonist. However, platelet function is not measured routinely during surgery as platelet function tests such as platelet aggregometry are timeconsuming and not available as a point-of-care test. Thus, there is no consensus on how to monitor primary hemostasis in liver transplantation.

\section{POINT-OF-CARE ASSAYS}

In many transplant centers, besides standard laboratory methods, point-of-care assays are gaining increasing acceptance as the speed with which their results are delivered make their use preferable to conventional laboratory based coagulation tests [51,85-87]. In addition, the point-of-care tests provide a continuous assessment of formation and dissolution of clot, in contrast to most conventional coagulation tests, which end their measurement when clots begin to form. By analyzing the whole blood sample in vitro, global hemostatic information can be obtained, from the onset of coagulation to complete clot formation and fibrinolysis.

\section{TEG}

TEG measures the clot's physical property by using a stationary cylindrical cup that holds a whole blood sample, with or without citrate and incubated in a cup at $37^{\circ} \mathrm{C}$. The cup oscillates through an angle of $4^{\circ} 45^{\prime}$, back and forth six times per minute. A stationary pin is immersed into the sample and attached to a torsion wire, which can monitor movements. After the activation of the coagulation cascade, the thrombin formation starts and consequently fibrinogen is converted to fibrin. As fibrin polymers are stabilized by factor VIII and activated platelets, a stable clot is formed and the torsion of the rotation cup is transmitted to the immersed pin after [88]. Obviously, the clot strength influences the oscillation of the pin, with these dynamic changes converted to an electrical signal by a mechanical-electrical transducer. The curve which is eventually displayed as a typical TEG tracing reflects the different phases of the clotting process and enables qualitative evaluation of the individual steps involved. As the clot retracts or lyses, the fibrin-platelet bonds are broken and the cup motion is again diminished.

Thrombelastography was developed over 50 years ago [89], but only in the 1980s it was firstly used during orthotopic liver transplantation by Kang et al. as a bedside monitor of coagulation used to define the viscoelastic properties of the blood, providing information about platelet activation, fibrin formation, and clot retraction [37]. In his pioneering work Kang showed a decrease in packed red cell use after the introduction of TEG monitoring and using TEG-guided transfusion algorithms in LT. It has several advantages over standard methods for clinical coagulation monitoring. 
Firstly, it is a compact device that can be housed in the operating room and close to the patient; secondly, results can be obtained fairly quickly as the onset of clot formation happens within a few minutes. Further, definitive differential diagnosis of coagulopathy can be made by comparing multiple channels of TEG (with the addition for example of heparinase), allowing a tailoring of transfusion therapy selective replacement or pharmacologic therapy [90].

\section{ROTEM}

The Rotem thromboelastometry analyzer, which was introduced in 1995, is a compact and portable point-of-care assay instrument [91]. Its principles are based on thromboelastography, generating a similar trace to the TEG device, although it uses a modified technology: the signal of the pin suspended in the blood sample is transmitted via an optical detector system, not a torsion wire, and the movement is initiated from the pin, not the cup [92]. It also uses only citrated blood.

Although TEG and Rotem parameters measure similar aspects of coagulation, it has not yet been established whether they provide identical information or whether for instance the associated transfusion algorithms for the TEG and Rotem systems would trigger blood component intervention at the same time points during surgical bleeding. In a bleeding surgical patient, recommended perioperative transfusion practices in orthotopic liver transplantation are likely to differ according to the method of coagulation monitoring used (Rotem, TEG or conventional tests) [87].

\section{CONCLUSIONS}

Patients undergoing LT are usually characterized by an impaired synthesis of most of the coagulation factors with complex haemostatic defects, although emerging evidence and innovative testing suggest that the traditional concept of these patients having a bleeding tendency is not completely correct. Future clinical research should focus on the development and validation of alternative tests mimicking more closely what occurs in vivo and to explore their usefulness in the peri-operative setting of LT. TEG is a technique that can provide continuous observation and tracing of all the haemostatic functions that lead to clot formation and dissolution. Together with the design of new equipment and materials, modern TEG is becoming more popular and useful as a bedside tool during such major surgical interventions. Appropriate clinical studies and trials with such new devices are warranted to define more precisely what happens during LT in terms of coagulation and haemostasis and therefore how to apply the most efficient management strategy.

\section{REFERENCES}

[1] Bismuth H, Castaing D, Ericzon BG, et al. Hepatic transplantation in Europe: first report of the European Liver Transplant Registry. Lancet 1987; 2: 674-6.

[2] Starzl TE, Iwatsuki S, Van Thiel DH, et al. Evolution of liver transplantation. Hepatology 1982; 2: 614-36.

[3] Lisman T, Leebeek FW, de Groot PG. Haemostatic abnormalities in patients with liver disease. J Hepatol 2002; 37: 280-7.

[4] Caldwell SH, Hoffman M, Lisman T, et al. Coagulation disorders and hemostasis in liver disease: pathophysiology and critical assessment of current management. Hepatology 2006; 44: 1039-46.
[5] Warnaar N, Lisman T, Porte RJ. The two tales of coagulation in liver transplantation. Curr Opin Organ Transplant 2008; 13(3): 298-303.

[6] Ewe K. Bleeding after liver biopsy does not correlate with indices of peripheral coagulation. Dig Dis Sci 1981; 26: 388-93.

[7] Segal JB, Dzik WH. Paucity of studies to support that abnormal coagulation test results predict bleeding in the setting of invasive procedures: an evidence-based review. Transfusion 2005; 45: 1413 25.

[8] Diaz LK, Teruya J. Liver biopsy. New Engl J Med 2001; 344(26): 2030.

[9] Tripodi A, Salerno F, Chantarangkul V, et al. Evidence of normal thrombin generation in cirrhosis despite abnormal conventional coagulation tests. Hepatology 2005; 41: 553-8.

[10] Mannucci PM. Abnormal hemostasis tests and bleeding in chronic liver disease: Are they related? No. J Thromb Haemost 2006; 4: 721-3.

[11] Lisman T, Caldwell SH, Leebeek FWG, Porte RJ. Hemostasis in chronic liver disease - Is chronic liver disease associated with a bleeding diathesis? J Thromb Haemost 2006; 4: 2059-60.

[12] Tsochatzis EA, Senzolo M, Germani G, Gatt A, Burroughs AK. Systematic review: portal vein thrombosis in cirrhosis. Aliment Pharmacol Ther 2010; 31(3): 366-74.

[13] Northup PG, McMahon MM, Ruhl AP, et al. Coagulopathy does not fully protect hospitalized cirrhosis patients from peripheral venous thrombosis. Am J Gastroenterol 2006; 101: 1524-8.

[14] Steib A, Freys G, Lehmann C, Meyer C, Mahoudeau G Intraoperative blood losses and transfusion requirements during adult liver transplantation remain difficult to predict. Can J Anesth 2001; 48: 1075-9.

[15] Warnaar N, Molenaar IQ, Colquhoun SD, et al. Intraoperative pulmonary embolism and intracardiac thrombosis complicating liver transplantation: a systematic review. J Thromb Haemost 2008; 6: 297-302.

[16] de Boer MT, Christensen MC, Asmussen M, et al. The impact of intraoperative transfusion of platelets and red blood cells on survival after liver transplantation. Anesth Analg 2008; 106: 32-44.

[17] Mor E, Jennings L, Gonwa TA, et al. The impact of operative bleeding on outcome in transplantation of the liver. Surg Gynecol Obstet 1993; 176: 219-27.

[18] Ramos E, Dalmau A, Sabate A, et al. Intraoperative red blood cell transfusion in liver transplantation: influence on patient outcome, prediction of requirements, and measures to reduce them. Liver Transpl 2003; 9: 1320-7

[19] de Boer MT, Molenaar IQ, Hendriks HG, et al. Minimizing blood loss in liver transplantation: progress through research and evolution of techniques. Dig Surg 2005; 22: 265-75.

[20] Massicotte L, Lenis S, Thibeault L, et al. Effect of low central venous pressure and phlebotomy on blood product transfusion requirements during liver transplantations. Liver Transpl 2006; 12: $117-23$

[21] Steib A, Gengenwin N, Freys G, Boudjema K, Levy S, Otteni JC. Predictive factors of hyperfibrinolytic activity during liver transplantation in cirrhotic patients. Br J Anaesth 1994; 73: 645-8.

[22] Hendriks HG, van der Meer J, Klompmaker IJ, et al. Blood loss in orthotopic liver transplantation: a retrospective analysis of transfusion requirements and the effects of autotransfusion of cell saver blood in 164 consecutive patients. Blood Coagul Fibrinolysis 2000; 11 (Suppl 1): S87-S93.

[23] Navalgund AA, Kang Y, Sarner JB, et al. Massive pulmonary thromboembolism during liver transplantation. Anesth Analg 1988; 67: 400-2.

[24] Silva MA, Jambulingam PS, Gunson BK, et al. Hepatic artery thrombosis following orthotopic liver transplantation: a 10-year experience from a single centre in the United Kingdom. Liver Transpl 2006; 12: 146-51.

[25] Ishitani M, Angle J, Bickston S, Caldwell S, Isaacs R, Pruett T. Liver transplantation: incidence and management of deep venous thrombosis and pulmonary emboli. Transplant Proc 1997; 29: 2861-3.

[26] Gologorsky E, deWolf AM, Scott V, Aggarwal S, Dishart M, Kang $Y$. Intracardiac thrombus formation and pulmonary thromboembolism immediately after graft reperfusion in 7 patients undergoing liver transplantation. Liver Transpl 2001; 7: 783-9. 
[27] Lisman T, Porte RJ. Antiplatelet medication after liver transplantation: does it affect outcome? Liver Transpl 2007; 13: 644-6.

[28] Stahl RL, Duncan A, Hooks MA, et al. A hypercoagulable state follows orthotopic liver transplantation. Hepatology 1990; 12: 5538.

[29] Cerutti E, Stratta C, Romagnoli R, et al. Thromboelastogram monitoring in the perioperative period of hepatectomy for adult living liver donation. Liver Transpl 2004; 10: 289-94.

[30] Kang Y, Audu P. Coagulation and liver transplantation. Int Anesthesiol Clin 2006; 44(4): 17-36.

[31] Kirby RM, McMaster P, Clements D, et al. Orthotopic liver transplantation: postoperative complications and their management. Br J Surg 1987; 74: 3-11.

[32] Ramaker AJ, Meyer P, van der Meer J, et al. Effects of acidosis, alkalosis, hyperthermia and hypothermia on haemostasis: results of point of care testing with the thromboelastography analyser. Blood Coagul Fibrinolysis 2009; 20: 436-39.

[33] Kratzer MAA, Dieterich J, Denecke H, et al. Hemostatic variables and blood loss during orthotopic human liver transplantation. Transplant Proc 1991; 23: 1906-11.

[34] Loskutoff DJ, Edgington TE. Synthesis of a fibrinolytic activator and inhibitor by endothelial cells. Proc Natl Acad Sci USA 1977; 74: 3903-7.

[35] Emeis JJ, van den Hoogen CM, Jense D. Hepatic clearance of tissue-type plasminogen activator in rats. Thromb Haemost 1985; 54: $661-4$.

[36] Lewis JH, Bontempo FA, Awad SA, et al. Liver transplantation: intraoperative changes in coagulation factors in 100 first transplants. Hepatology 1989; 9: 710-4.

[37] Kang YG, Martin DJ, Marquez J, et al. Intraoperative changes in blood coagulation and thrombelastographic monitoring in liver transplantation. Anesth Analg 1985; 64: 888-96.

[38] Porte RJ. Coagulation and fibrinolysis in orthotopic liver transplantation: current views and insights. Semin Thromb Hemost 1993; 19: 191-6.

[39] Porte RJ, Knot EA, Bontempo FA. Hemostasis in liver transplantation. Gastroenterology 1989; 97: 488-501.

[40] Bakker CM, Blankensteijn JD, Schlejen P, et al. The effects of longterm graft preservation on intraoperative hemostatic changes in liver transplantation. A comparison between orthotopic and heterotopic transplantation in the pig. HPB Surg 1994; 7: 265-80.

[41] Porte RJ, Bontempo FA, Knot EA, et al. Systemic effects of tissue plasminogen activator-associated fibrinolysis and its relation to thrombin generation in orthotopic liver transplantation. Transplantation 1989; 47: 978-84.

[42] Kang Y, Lewis JH, Navalgund A, et al. Epsilon-aminocaproic acid for treatment of fibrinolysis during liver transplantation. Anesthesiology 1987; 66: 766-73.

[43] Harding SA, Mallett SV, Peachey TD, Cox DJ. Use of heparinase modified thromboelastography in liver transplantation. $\mathrm{Br} \mathrm{J}$ Anaesth 1997; 78: 175-9.

[44] Pivalizza E, Abramson D, King F. Thromboelastography with heparinase in orthotopic liver transplantation. J Cardiothor Vasc Anesth 1998; 12: 305-825.

[45] Senzolo M, Cholongitas E, Thalheimer U, et al. Heparin-like effect in liver disease and liver transplantation. Clin Liver Dis 2009; 13(1): 43-53.

[46] Moriau M, Kestens PJ, Masure R. Heparin and antifibrinolytic agents during experimental hepatectomy and liver transplantation. Pathol Eur 1969; 4: 172-82.

[47] Bellani KG, Estrin JA, Ascher NL, et al. Reperfusion coagulopathy during human liver transplantation. Transplant Proc 1987; 19(4 Suppl 3): 71-2.

[48] Chapin JW, Peters KR, Winslow J, et al. Circulating heparin during liver transplantation. Transplant Proc 1993; 25(2): 1803.

[49] Pivalizza EG, Abramson DC, King FS Jr. Thromboelastography with heparinase in orthotopic liver transplantation. J Cardiothorac Vasc Anesth 1998; 12(3): 305-8.

[50] Kettner SC, Gonano C, Seebach F, et al. Endogenous heparin-like substances significantly impair coagulation in patients undergoing orthotopic liver transplantation. Anesth Analg 1998; 86(4): 691-5.

[51] Agarwal S, Senzolo M, Melikian C, et al. The prevalence of a heparin-like effect shown on the thromboelastograph in patients undergoing liver transplantation. Liver Transpl 2008; 14(6): 85560 .
[52] Groth CG, Pechet L, Starzl TE. Coagulation during and after orthotopic transplantation of the human liver. Arch Surg 1969; 98 : 31-34.

[53] Senzolo M, Agarwal S, Zappoli P, et al. Heparin-like effect contributes to the coagulopathy in patients with acute liver failure undergoing liver transplatation. Liver Int 2009; 29(5): 754-9.

[54] McKee RF, Hodson S, Dawes J, et al. Plasma concentrations of endogenous heparinoids in portal hypertension. Gut 1992; 33(11): $1549-52$.

[55] Sindram D, Porte RJ, Hoffman MR, Bentley RC, Clavien PA. Platelets induce sinusoidal endothelial cell apoptosis upon reperfusion of the cold ischemic rat liver. Gastroenterology 2000; 118: 183-91.

[56] Himmelreich G, Hundt K, Neuhaus P, Roissant R, Riess H. Decreased platelet aggregation after reperfusion in orthotopic liver transplantation. Transplantation 1992; 53: 582-6.

[57] Himmelreich G, Hundt K, Isenberg C, Bechstein WO, Neuhaus P, Riess H. Thrombocytopenia and platelet dysfunction in orthotopic liver transplantation. Semin Thromb Hemost 1993; 19: 209-12.

[58] Schalm SW, Terpstra JL, Achterberg JR, et al. Orthotopic liver transplantation: an experimental study on mechanisms of hemorrhagic diathesis and thrombosis. Surgery 1975; 78: 499-507.

[59] Porte RJ, Blauw E, Knot EA, et al. Role of the donor liver in the origin of platelet disorders and hyperfibrinolysis in liver transplantation. J Hepatol 1994; 21: 592-600.

[60] Pereboom IT, Lisman T, Porte RJ. Platelets in liver transplantation: friend or foe? Liver Transpl 2008; 14(7): 923-31.

[61] Richards EM, Alexander GJ, Calne RY, Baglin TP. Thrombocytopenia following liver transplantation is associated with platelet consumption and thrombin generation. Br J Haematol 1997; 98: 315-21.

[62] Faeh M, Hauser SP, Nydegger UE. Transient thrombopoietin peak after liver transplantation for end-stage liver disease. Br J Haematol 2001; 112: 493-8.

[63] Mehta AB, Burroughs AK. Thrombopoietin concentration after orthotopic liver transplantation. Br J Haematol 2001; 114(4): 9601.

[64] Goulis J, Chau TN, Jordan S, et al. Thrombopoietin concentrations are low in patients with cirrhosis and thrombocytopenia and are restored after orthotopic liver transplantation. Gut 1999; 44: 754-8.

[65] Sutedja DS, Wai CT, Teoh KF, et al. Persistent thrombocytopenia in liver transplant patients. Transplant Proc 2004; 36: 2331-3.

[66] Marubashi S, Dono K, Miyamoto A, et al. Impact of graft size on postoperative thrombocytopenia in living donor liver transplant. Arch Surg 2007; 142: 1054-8.

[67] Seth AK, Gunson BK, Mirza BF, Haydon G. Thrombocytosis in liver transplant recipients: prevalence, natural history, and impact. Liver Transpl 2007; 13: 1598-602.

[68] Segal JB, Dzik WH. Paucity of studies to support that abnormal coagulation test results predict bleeding in the setting of invasive procedures: an evidence-based review. Transfusion 2005; 45: 1413 25.

[69] Gerlach H, Gosse F, Rossaint R, et al. The relevance of perioperative coagulation parameters to indications for blood transfusion. A retrospective analysis of 300 liver transplantations. Anaesthesist 1994; 43: 168-77.

[70] Ozier Y, Pesione F, Samain E, et al. Institutional variability in transfusion practice for liver transplantation. Anesth Analg 2003; 97: 671-9.

[71] Massicotte L, Sassine MP, Lenis S, et al. Transfusion predictors in liver transplant. Anesth Analg 2004; 98: 1245-51.

[72] Quick AJ. The prothrombin in hemophilia and in obstructive jaundice. J Biol Chem 1935; 109: 73-4.

[73] Wiesner R, Edwards E, Freeman R, et al. United Network for Organ Sharing Liver Disease Severity Score Committee. Model for end-stage liver disease (MELD) and allocation of donor liver. Gastroenterology 2003; 124: 91-6.

[74] Trotter JF, Brimhall B, Arjal R, Phillips C. Specific laboratory methodologies achieve higher model for endstage liver disease (MELD) scores for patients listed for liver transplantation. Liver Transpl 2004; 10: 995-1000.

[75] van den Besselaar AMHP, Poller L, Tripodi A. Guidelines for thromboplastins and plasmas used to control oral anticoagulant therapy (1999). WHO Tech Rep Ser 1999; 889: 64-93. 
[76] Kovacs MJ, Wong A, MacKinnon K, et al. Assessment of the validity of the INR system for patients with liver impairment. Thromb Haemost 1994; 71: 727-30.

[77] Tripodi A, Chantarangkul V, Primignani M, et al. The international normalized ratio calibrated for cirrhosis (INRliver) normalizes prothrombin time results for model for end-stage liver disease calculation. Hepatology 2007; 46: 520-7.

[78] Bellest L, Eschwege V, Poupon R, et al. A modified international normalized ratio as an effective way of prothrombin time standardization in hepatology. Hepatology 2007; 46: 528-34.

[79] Langdell RD, Wagner RH, Brinkhous KM. Effect of antihemophilic factor on onestage clotting tests; a presumptive test for hemophilia and a simple one-stage antihemophilic factor assay procedure. J Lab Clin Med 1953; 41: 637-47.

[80] Proctor RR, Rapaport SI. The partial thromboplastin time with kaolin. A simple screening test for first stage plasma clotting factor deficiencies. Am J Clin Pathol 1961; 36: 212-9.

[81] Hutchison DE, Genton E, Porter KA, et al. Platelet changes following clinical and experimental hepatic homotransplantation. Arch Surg 1968; 97: 27-33.

[82] Owen CA, Rettke SR, Bowie EJW, et al. Hemostatic evaluation of patients undergoing liver transplantation. Mayo Clin Proc 1987; 62: 761-72.

[83] Mammen EF, Comp PC, Gosselin R, et al. PFA-100 system: a new method of assessment of platelet dysfunction. Semin Thromb Hemost 1998; 24: 195-202.

[84] Chang YW, Liao CH, Day YJ. Platelet function analyzer (PFA100) offers higher sensitivity and specificity than thromboelastography (TEG) in detection of platelet dysfunction. Acta Anaesthesiol Taiwan 2009; 47(3): 110-7.

[85] Kang Y. Transfusion based on clinical coagulation monitoring does reduce hemorrhage during liver transplantation. Liver Transpl Surg 1997; 3: 655-9.

[86] Coakley M, Reddy K, Mackie I, Mallett S. Transfusion triggers in orthotopic liver transplantation: a comparison of the thromboelastometry analyzer, the thromboelastogram, and conventional coagulation tests. J Cardiothor Vas Anesth 2006; 20: 548-53.

[87] Görlinger K, Dirkmann D, Hanke A, Dusse F, Hartmann M. ROTEM-based algorithm for point of-care coagulation management in visceral surgery and liver transplantation: experience of eight years and 829 LTX. Liver Transpl 2008; 14(Suppl 1): LB485.

[88] Bombeli T, Spahn DR. Updates in perioperative coagulation physiology and management of thromboembolism and haemorrhage. Crit Care 2004; 93(2): 275-87.

[89] Hartert H. Blutgerinnungstudien mit der Thrombelastographie, einem neuen Untersuchungsverfahren. Klin Wochenschrift 1948; 26: 557-83.

[90] Kang Y. Thromboelastography in liver transplantation. Semin Thromb Hemost 1995; 21(Suppl 4): 34-44.

[91] Calatzis AN, Fritzche P, Kling M, et al. A new technique for fast and specific intraoperative coagulation monitoring. Eur Surg Res 1996; 28: 89. (abstr).

[92] Luddington RJ. Thromboelastography/thromboelastometry. Clin Lab Haematol 2005; 27: 81-90.

(C) Garcovich et al.; Licensee Bentham Open.

This is an open access article licensed under the terms of the Creative Commons Attribution Non-Commercial License (http://creativecommons.org/ licenses/by-nc/3.0/), which permits unrestricted, non-commercial use, distribution and reproduction in any medium, provided the work is properly cited. 